\title{
La dinámica del paisaje en la Serra d'Aitana (Alacant, España): síntesis de transformaciones históricas en una montaña mediterránea (1600-2010)
}

\section{The dynamics of the landscape in the Serra d'Aitana (Alicante, Spain): synthesis of historical transformations in a Mediterranean mountain (1600-2010)}

\author{
Pablo Giménez-Font ${ }^{1}$ y Juan Antonio Marco Molina ${ }^{2}$
}

\begin{abstract}
RESUMEN
El estudio sobre la trayectoria histórica de los ecosistemas es necesario para comprender su capacidad de respuesta ante determinadas perturbaciones. A partir de esta idea, el presente trabajo analiza las transformaciones del paisaje ocurridas en los últimos 400 años en la Serra d'Aitana, un espacio singular que reúne las principales características ecológicas e históricas de la montaña media mediterránea europea. El artículo sintetiza los resultados de una larga investigación en la que se han empleado numerosas fuentes documentales, orales y de trabajo de campo. Los resultados se ofrecen en cinco periodos (hasta 1650, 1650-1850, 1850-1920, 1920-1960 y 1960-2010) que permiten comprobar la intensidad de los cambios ocurridos a partir de cinco procesos: expansión de la superficie agraria, ganadería, incendios forestales, aprovechamientos forestales y repoblaciones forestales. De esta forma se obtiene un marco analítico general que permitirá centrar posteriores estudios de detalle en las montañas béticas valencianas.
\end{abstract}

1 Departamento de Análisis Geográfico Regional y Geografía Física. Universidad de Alicante. pablo.gimenez@ua.es. ORCID iD: http://orcid.org/0000-0002-1171-715X.

2 Departamento de Análisis Geográfico Regional y Geografía Física. Universidad de Alicante. ja.marco@ua.es. ORCID iD: http://orcid.org/0000-0003-3431-0499. 
Palabras Clave: Montaña mediterránea; presión antropogénica; historia del paisaje; Aitana; Valencia.

\begin{abstract}
The study of how ecosystems develop is essential in order to understand their capacity of response to specific disturbances. Based on this idea, this paper analyses the transformations that have occurred over the last 400 years in the Serra d'Aitana, a singular area combining the typical ecological and historical features of a European Mediterranean mountain range. The article summarises the results of extensive research which has used numerous sources, both documented and oral, along with field work. The results are presented in five periods (up to 1650, 1650-1850, 1850-1920, 1920-1960 and 1960-2010) which check the intensity of the changes from five processes: expansion of agricultural land, livestock, forest fires, forestry and reforestation. This provides a general analytical framework which will facilitate the work of future, more detailed studies of the Valencia Baetic mountain range.
\end{abstract}

KEY WORDS: Mediterranean mountains; environmental anthropopression; landscape history; Aitana; Valencia.

Cómo citar este artículo / Citation: Giménez-Font, Pablo y Marco Molina, Juan Antonio (2017): "La dinámica del paisaje en la Serra d'Aitana (Alacant, España): síntesis de transformaciones históricas en una montaña mediterránea (1600-2010)", Estudios Geográficos, LXXVIII/282, pp. 105-133.

\title{
INTRODUCCIÓN
}

A lo largo de las últimas décadas y en el marco del Convenio Europeo del Paisaje, se han incrementado los estudios sobre la dinámica temporal de los paisajes rurales europeos, dada la dimensión histórica de los mismos y la necesidad creciente de comprender su estructura y funcionamiento para una correcta gestión y conservación (Antrop, 2005; Agnoletti, 2014; Plieninger et al., 2015). El ámbito mediterráneo y, en concreto, su montaña media, ha sido objeto de estudio desde diversos enfoques, especialmente relacionados con los cambios en los usos del suelo y en la gestión de los recursos naturales (Naveh, 1991; Poyatos et al., 2003; Vogiatzakis y Papanastasis, 2012; Lasanta et al., 2005 y 2016). Sin embargo, no son comunes los estudios basados en periodos prolongados, más allá de la segunda mitad del siglo XIX o, principalmente, con carácter previo a 1950. Esto es debido a la disponibilidad de fuentes como los documentos catastrales o la fotografía aérea, que permiten reconstrucciones y análisis retrospectivos de alta calidad (Kull, 2005; Marull, 2006; Agnoletti, 
2007). Por otro lado, la indudable interrelación entre el medio y las distintas civilizaciones que han ocupado las riberas del Mediterráneo (Grove y Rackham, 2001; Butzer, 2005), ha facilitado la reproducción de estudios arqueológicos sobre el paisaje — especialmente sobre la vegetación - hasta superar en número a los análisis dedicados a los últimos tres o cuatro siglos. De esta forma, puede hablarse de cierta paradoja al encontrar tantos o más artículos de investigación sobre el paisaje de la primera mitad del Holoceno o del período romano en el Mediterráneo que del propio paisaje del siglo XVI y XVII. Ante esta dualidad entre periodos de análisis que no superan el siglo y otros que sobrepasan los milenios, conviene destacar que uno de los temas de estudio más relevantes en los últimos años se refiere a la relación entre los cambios en el paisaje y la biodiversidad (Foster et al., 2003); perspectiva que gana solidez cuando se realiza con parámetros históricos de medio plazo, donde los agentes de perturbación son eminentemente antropogénicos y las huellas de la actividad humana puede reconocerse y analizarse de forma más fiable sobre el paisaje actual.

Atendiendo a estas ideas, recientemente se han redefinido dos de las principales prioridades en el estudio del cambio global en los ecosistemas mediterráneos (Doblas-Miranda et al., 2015): analizar cómo varía la biodiversidad con las transformaciones del paisaje y conocer la historia y funcionamiento de un ecosistema para comprender su capacidad de respuesta ante determinadas perturbaciones, como la deforestación relacionada con la ampliación del espacio agrario o la incidencia de grandes incendios forestales. Por esta razón, el presente estudio plantea un análisis de las transformaciones ocurridas durante los últimos 400 años en un espacio singular de montaña media mediterránea. Los resultados permiten explicar cómo la máxima degradación, en términos ecológicos, se alcanzó hace 150 años, por lo que la situación actual se puede contextualizar dentro de la capacidad de respuesta de los ecosistemas - haciendo especial incidencia en la vegetación- a la perturbación producida por la intensificación del aprovechamiento, poco eficiente, de los recursos naturales. En esta línea McNeill (1994) señala un proceso común en las montañas del mediterráneo, aunque su planteamiento - en la línea de pensamiento de Marsh (1864) sobre la degradación acumulativa del paisaje mediterráneo- ha sido acusado de excesivamente determinista al considerar los procesos de deforestación y desertificación como fenómenos recientes y relacionarlos en exceso con el crecimiento demográfico. La clásica obra de Braudel (1953) e incluso las más recientes de Horden y Purcell (2000) y Grove y Rackham (2001) ofrecen puntos de vista más completos y relatan la necesidad de dotar la discusión de estudios de caso detallados. A partir de este marco general, los testimonios 
contemporáneos y estudios realizados en el contexto regional (Reino de Valencia) apuntan a estados elevados de degradación de la vegetación ya a finales del siglo XVIII, en relación con fenómenos expansionistas de las tierras de cultivo (Asins, 2009) y el incremento de la población, con cambios significativos en la extensión y composición de la vegetación de los montes (Cavanilles, 17951797; de La Croix, 1801; Bauer, 1980; Ferrer, 2008). La documentación a partir de estas fechas es relativamente abundante y permite análisis más detallados, pero el siglo XVII e inicios del XVIII resultan periodos más desconocidos. Por todo ello, se hacen necesarios estudios de detalle sobre zonas representativas, donde realizar primeramente una periodización que permita conocer la evolución de la organización tradicional del espacio -incluyendo así la gestión de los recursos naturales-y localizar los principales momentos de cambio, así como los factores impulsores de dichas transformaciones del paisaje.

\section{MÉTODOS}

\section{Área de estudio}

La Serra d'Aitana es conjunto morfoestructural definido como horts-cresta basculado (Marco, 1990) que, con su cima a $1.558 \mathrm{msnm}$., representa la culminación del apéndice peninsular más oriental de la Cordillera Bética. Junto a su altitud, la disposición zonal del bloque culminante introduce contrastes destacables con respecto a los espacios circundantes: pluviometría, innivación y diversidad de ecótopos, muchos de los cuales están relacionados con una intensa y antigua humanización.

Con predominio de litología calcárea, el conjunto montañoso se halla enmarcado por una serie de fosas tectónicas - valles- donde la presencia de materiales blandos - margas y depósitos cuaternarios - ha permitido el aprovechamiento agrícola mediante la conformación de un inmenso paisaje de terrazas de cultivo. La composición y dimensión del relieve permite la alimentación, eminentemente kárstica, de tres cuencas fluviales: Riu Frainos, Riu Guadalest y Riu Amadorio. Los dos últimos desembocan en llanos litorales situados a pocos kilómetros, formando abanicos aluvio-coluviales, puesto que otra característica destacable de la zona de estudio es su proximidad al mar (figura 1). En realidad, Aitana era un elemento destacado del territorio histórico que, hasta bien entrado el siglo xviI, se denominó Quartel de la Marina y las Montañas (Escolano, 1611) y que en la actualidad abarcaría aproximadamente el contacto entre el norte de la Provincia de Alicante y el sur de la 
de Valencia. Ámbito que resulta especialmente sugerente porque allí concurren los grandes elementos definidores del mundo Mediterráneo (Horden y Purcell, 2000): el llano litoral adosado a estructuras montañosas, los microambientes derivados del relieve, las trayectorias locales en un contexto sociológico compartido, la influencia histórica del comercio; en definitiva, la intensa humanización de un medio ecológico adaptado a las perturbaciones derivadas de un clima irregular, pero también de los cambios culturales que supuso la sucesión de pueblos y civilizaciones, no siempre de forma pacífica.

\section{FIGURA 1}

\section{LOCALIZACIÓN DEL ÁREA DE ESTUDIO}

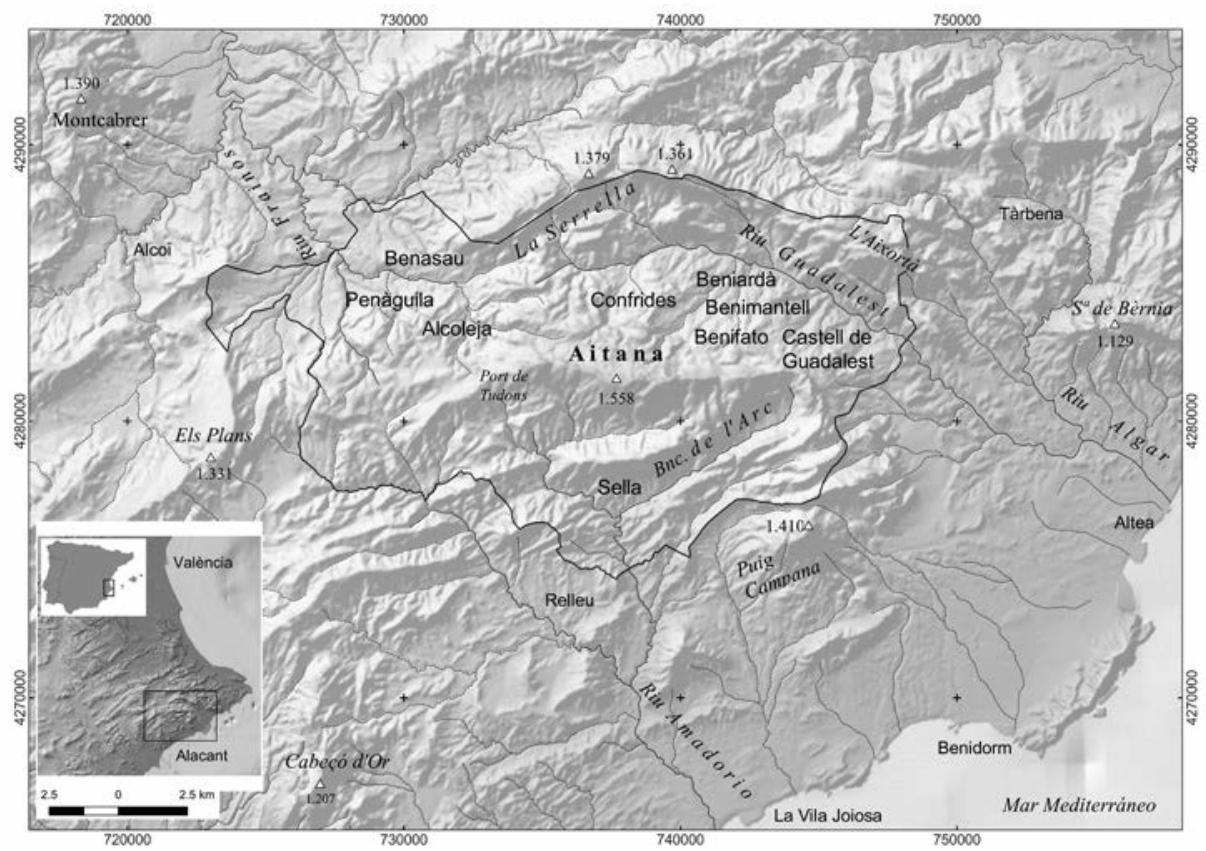

Fuente: elaboración propia con datos provenientes de CNIG e ICV.

\section{Marco metodológico}

En esta prolongada historia, conviene detenerse en los últimos siglos porque, siguiendo a García Fernández (2002) o Glick (2007), la conquista cristiana supuso la implantación progresiva - a largo plazo y a gran escala - de una 
nueva organización del espacio relacionada con estructuras sociales y percepciones del medio diferentes a las que existían en el mundo rural de al-Andalus. La incorporación de la Serra d'Aitana al Reino de Valencia se produjo, con dificultades de orden bélico, en el siglo XIII, pero la población mudéjar —más tarde morisca - fue predominante en la mayoría de los pequeños valles intramontanos, aspecto que determinó su marginalidad respecto al avance económico de otros sectores circundantes (Torró, 2006). El problema del corsarismo berberisco y del poblamiento indígena en el interior concentró a la mayoría de los colonos cristianos en poblaciones fortificadas del litoral. Salvo núcleos puntuales de cristianos viejos y de realengo como Penàguila, la implantación de la jurisdicción señorial fue muy importante, lo que determinó parte de la organización del territorio. La presión que durante tres siglos sufrió la población islámica, incluyendo su conversión forzosa al cristianismo a mediados del s. XVI, estuvo salpicada de sublevaciones, deportaciones y una emigración más o menos constante hasta la definitiva y traumática expulsión de los moriscos en 1609. A partir de este momento, se inició un lento proceso colonizador, dificultoso en un primer momento, bajo nuevas normas de relación entre señores y vasallos.

Estas características históricas permiten realizar lecturas de tipo ecológico: nos indican los contextos de partida — relativos a la conflictividad y las normas sociales- en los que se desarrollaron las comunidades rurales desde hace, al menos, 500 años. Con este planteamiento, la marginalidad de este territorio moderadamente aislado es una oportunidad para tratar de reconstruir el paisaje. Para ello se ha centrado el interés en territorios con recorridos históricos compartidos sobre una base ecológica común. De esta forma, los resultados del presente análisis pueden extrapolarse al conjunto de esas comarcas centrales valencianas y sus pequeños y numerosos valles intramontanos. Espacios donde se construyó un paisaje rural relativamente reciente -representado por las terrazas de cultivo- $\mathrm{y}$ donde se han producido cambios importantes en las últimas décadas relacionados con el abandono de la actividad agrícola que los caracterizó desde hace, al menos, tres siglos. Estas particularidades junto con unas características ecológicas singulares las han hecho merecedoras, en la línea de otras zonas de montaña media mediterránea de Europa, de distintas figuras de protección enmarcadas en la directiva Habitats de la UE. En el caso de la Serra d'Aitana, hay que destacar el LIC "Aitana, Serrella y Puig Campana", que coincide con la ZEPA "Montañas de La Marina". A escala autonómica, seis Microrreservas de flora protegen hábitats y taxones prioritarios (Padilla, 2006). Aunque fuera del área estricta de este estudio, en contacto con la misma se localizan el Paisaje protegido "Puig Campana y Ponoig" (Finestrat, La Nucía, Benidorm y Polop) y el Paraje Natural Municipal "Els Arcs" (Castell de Castells) (figura 2). 
FIGURA 2

FIGURAS DE PROTECCIÓN QUE AFECTAN A LA SERRA D'AITANA

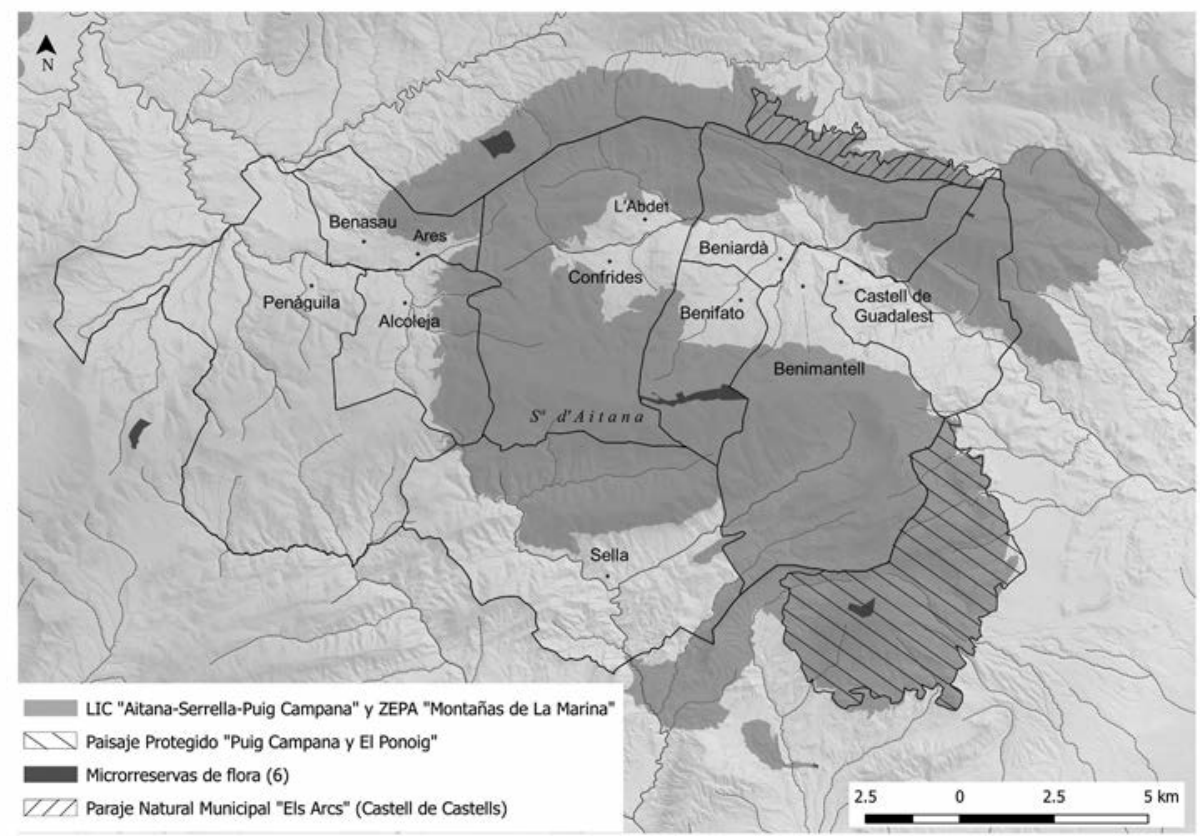

Fuente: elaboración propia con datos provenientes de ICV (Infraestructura verde de la Comunitat Valenciana).

\section{Fuentes}

Los resultados de este estudio se sustentan, principalmente, en más de 25 años de experiencia en el análisis del medio físico y las relaciones entre éste y el ser humano en la Serra d'Aitana (Marco, 1989). Este bagaje científico permite contar con cartografía geomorfológica (Marco, 1990; Marco et al., 2000) y de poblamientos vegetales (Marco, 2001; Marco et al., 2006), junto con numerosos transectos de vegetación (Padilla, 1998; Marco y Padilla, 2002) y estudios relativos a la organización tradicional del espacio y la gestión histórica de los recursos naturales (Marco, 2001; Giménez-Font, 2008 y 2013). Sobre este último aspecto se hacía necesaria una revisión que, partiendo de los postulados básicos del aprovechamiento de la montaña media mediterránea (García Fernández, 2002), permitiera datar grandes momentos de cambio 
paisajístico en los últimos siglos, entender los factores de dichas transformaciones y definir las principales características del paisaje vegetal en determinadas épocas. De forma transversal para los periodos analizados el prolongado trabajo de campo y la recuperación de memoria oral mediante entrevistas han sido determinantes para entender la organización tradicional del espacio, junto con las distintas colecciones de fotografía aérea (vuelos de 1945, 1956, 1978, 1985, 1994 y las ortofotos de 1998 y del PNOA a partir de la década de 2000). Por otro lado, la documentación histórica y la bibliografía han resultado fundamentales para comprender el paisaje de los siglos XVII, XVIII y XIX. A este respecto cabe destacar los estudios sobre el proceso de repoblación cristiana y el estudio de Cartas Puebla en la zona (Pla Alberola, 1983, 1991; Torró, 1990; Bernat y Badenes, 1994, Martines et al., 2009), con notas sobre historia forestal (Ferrer, 2004; Marco, 2010). Aspectos que se han complementado con la documentación localizada en distintos archivos (ARV, AHN, ARP, ADA, AHPA, AMV), noticias de prensa histórica, testimonios contemporáneos (Nipho, 1770-1771; Cavanilles, 1795-97; Castañeda y Alcover, 1919; Madoz, 1845; Martí y Gadea, 1901) y fotografía histórica, con imágenes disponibles desde finales del siglo XIX (Giménez-Font, 2010). La cuantificación de la evolución de superficies roturadas por épocas no ha sido posible más que para algunas localidades y para determinados momentos: establecimientos de tierras que acompañan a las cartas puebla (Benimantell, 1611), Cabreves (Sella, 1726) o expedientes emitidos por el Real Patrimonio (Penàguila, 1815-1866). No obstante se trata de un voluminoso conjunto de datos que evidencian los procesos que se explican a continuación. La estructura de los periodos descritos se ha planteado a partir de la relación de principales variables que intervienen en los cambios del paisaje: evolución de la población, tipo de poblamiento o aspectos sociales, jurisdiccionales y económicos. La síntesis representada en la figura 5 ha tenido en cuenta estos factores junto con la intensidad de los procesos con mayor impacto sobre la vegetación: incendios, expansión de cultivos, ganadería, aprovechamientos forestales y repoblaciones.

\section{RESULTADOS}

\section{Antecedentes hasta 1650: desintensificación}

Durante el siglo xvi el proceso de marginación de la población morisca de la montaña, los conatos de rebeliones y la creciente coacción por parte de los 
dominadores cristianos provocaron movimientos migratorios e inestabilidades sociales tales que no permiten concretar cifras de población. Las estimaciones hechas para el área de estudio apuntan a unos 3.600 habitantes, repartidos en 25 núcleos de población documentados, de los cuales únicamente Penàguila y El Castell de Guadalest mantenían población cristiana (aproximadamente un 25\% del total). A pesar de la adaptación a las exigencias del nuevo sistema productivo impulsado tras la conquista en el siglo XIII -basado, entre otros aspectos, en la expansión de las roturaciones de nuevas tierras de cultivo (Torró, 2005) - se mantuvo la agricultura intensiva de regadío concentrada en los entornos de los asentamientos, con una relativamente escasa expansión del secano y el mantenimiento de la ganadería trashumante y transterminante. Según el censo de 1510 (García Cárcel, 1977), las actuales comarcas que conforman La Marina mantenían el mayor número de cabezas de ganado (27.385) del sur del Reino de València, predominando rebaños de tipo medio (100-500 cabezas). No en vano, el Quartel de La Marina y las Montañas conservaba el tercer lugar en importancia ganadera de todo el reino, por detrás de Els Ports - Maestrat y Javalambre (Obiol, 1997); aprovechamiento que determinaría el tipo y estado de paisaje vegetal predominante, teniendo en cuenta la importancia superficial de los espacios de monte o del incultum que señalan las Cartas Puebla emitidas tras la expulsión (figura 3).

Con la expulsión de los moriscos en 1609 el entorno de la Serra d'Aitana perdió un $75 \%$ de su población y los años posteriores se caracterizaron por una lenta y costosa repoblación, lo que redujo claramente la presión humana sobre el medio y facilitó la recuperación de la vegetación natural. En la mayor parte de los pueblos situados en el área de estudio, se tardaron varias décadas en conseguir fijar población y las referencias al predominio de campos abandonados (Pla, 1983) demuestra cómo la expulsión representó un mecanismo radical de desintensificación. De hecho, la referencia más antigua que se dispone de un incendio de grandes proporciones en Aitana es el ocurrido en un pinar cercano a Alcoleja en 1613 (Portús y Vega, 1998), que podría relacionarse con ese proceso generalizado de abandono. 
FIGURA 3

EVOLUCIÓN DE LA DISTRIBUCIÓN PORCENTUAL DE SUPERFICIES CULTIVADAS E INCULTAS 1611, 1956 Y 2000*
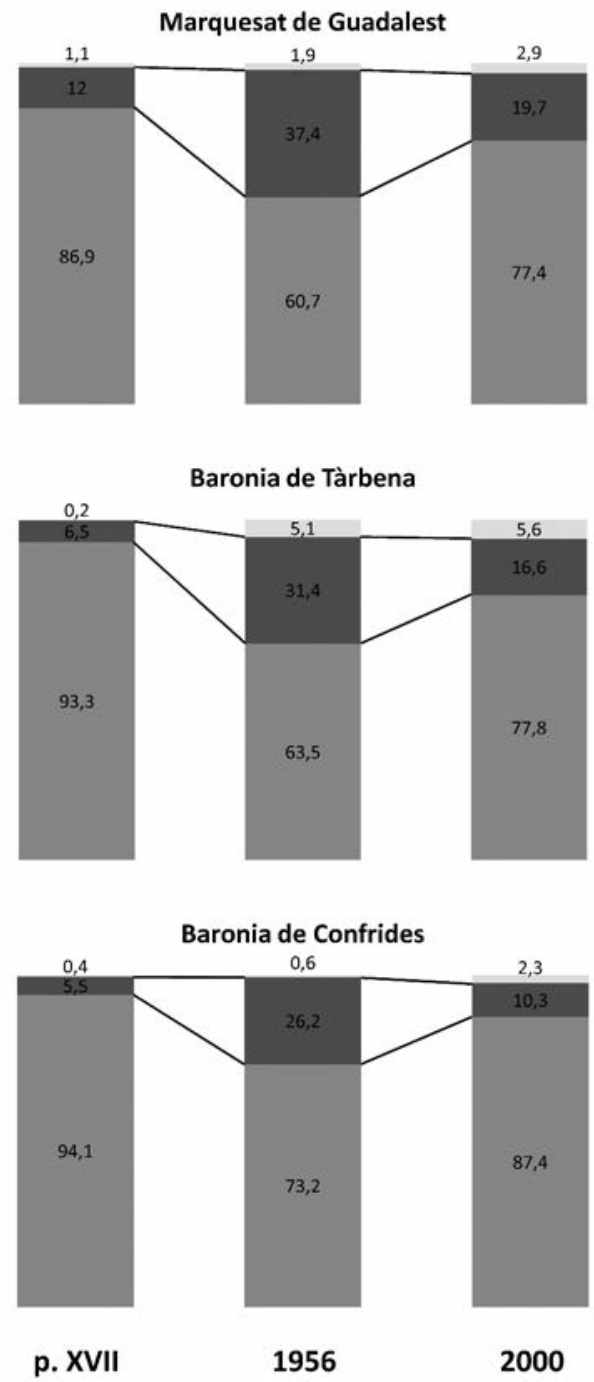

\section{घnculto $\square$ Secano $\square$ Regadío}

Fuent-es: elaboración propia a partir de Pla Alberola (1983); Corbalán de Celis (2004); Peña et al. (2007). *(\% respecto al total del término municipal): aunque se incluyen los espacios artificiales, su representatividad porcentual es mínima a los efectos buscados. 


\section{Colonización agraria (1650-1850): intensificación}

La fijación inicial de población — con el reparto de lotes de tierra y la formación de nuevas comunidades rurales- fue costosa y se alargó durante décadas, pero puede considerarse que durante la segunda mitad del siglo XVII y las primeras décadas del XVIII se había consolidado el proceso colonizador en la Serra d'Aitana. Las bases de una nueva sociedad, presentes en las cartas de población, incluyeron un cambio en las pautas de asentamiento con una simplificación de la red de poblamiento (Pla, 1983). Todavía en 1790 se contabilizaban 16 despoblados, a pesar de que el incremento de la población se aceleró sensiblemente a partir de la segunda mitad del siglo xviII. Entre los censos de 1730 y 1768, la población ya se había multiplicado por tres, superando los 7.000 habitantes a finales de dicha centuria. Este crecimiento tan notable se acompañó — dentro de un cuadro de estabilidad social muy diferente al que caracterizó a la sociedad morisca- de un predominio del contrato enfitéutico mediante la figura del establiment, que supuso un lento pero contundente impulso roturador relacionado con cultivos de orientación comercial, como el trigo y la vid (Gil Olcina, 1988). En consecuencia, este hecho significó un incremento, cuando no el inicio, de la construcción de grandes sistemas de terrazas de cultivo, desarrolladas masivamente hasta el siglo XIX sobre espacios de monte, de dedicación forestal y ganadera. Por las noticias recopiladas ${ }^{3}$, los rompimientos de tierras se realizaron a pequeña escala, pero la importancia del proceso aumenta a escala agregada y permite explicar los fenómenos expansionistas vividos en algunos municipios junto con sus dinámicas asociadas, como el crecimiento del poblamiento diseminado o el establecimiento y ampliación de molinos. Tampoco hay que olvidar las mancomunidades y los flujos comarcanos de suministro de materias provenientes del monte, que se desarrollaron entre municipios del interior y pueblos y ciudades litorales, como Alacant, Altea o La Vila Joiosa.

A pesar de un estancamiento generalizado de la economía en las primeras décadas del siglo XIX, los cambios institucionales que se produjeron en España a partir de 1830, relacionados con la disolución del régimen señorial y las políticas desamortizadoras, culminaron con un impulso roturador sin parangón (Montiel, 1995), que se aceleró a partir de la década de 1860.

La expansión de los cultivos y la intensificación de usos tienen una repercusión directa sobre la vegetación natural, progresivamente más degradada se-

${ }^{3}$ Entre otras, destacan las relativas a Alcoleja, Sella o Benimantell, analizadas en GiménezFont (2013) y provenientes de cabreves y protocolos notariales. 
gún diversos testimonios. La utilización del fuego para la obtención de pastos parece una práctica común (AMV), acorde con el peso relativo de la ganadería (censo ganadero de 1865). En la década de 1850 aparecen documentadas las primeras repoblaciones, que con escasa importancia se realizan generalmente con Pinus halepensis en Penàguila, Benifallim o Relleu, entre otros (Marco, 2001: 79).

\section{La saturación de la montaña (1850-1920)}

Durante la segunda mitad del siglo XIX, los pueblos del entorno de Aitana alcanzaron su máximo poblacional hasta superar los 8.500 habitantes. Alrededor de un $30 \%$ de estos lo hacían diseminados en masías, una unidad de explotación básica del territorio valenciano que se consolida junto con las nuevas roturaciones de los siglos XVIII y XIX (tabla 1).

TABLA 1

EVOLUCIÓN DEL POBLAMIENTO DISPERSO EN CINCO MUNICIPIOS (1790-1878)

\begin{tabular}{l|c|l|l}
\hline \multicolumn{1}{c|}{ Municipio } & Extensión $\mathrm{km}^{2}$ & \multicolumn{1}{c|}{1791} & 1878 \\
\hline Castell de Guadalest & 15,97 & $\begin{array}{l}\text { 9 casas, 2 núcleos y } \\
4 \text { despoblados }\end{array}$ & 86 casas \\
\hline Beniardà & 15,74 & \multirow{2}{*}{20 casas y 7 despoblados } & 39 casas \\
\cline { 1 - 4 } Benifato & 11,9 & 20 casas y 2 núcleos & 15 casas \\
\hline Benimantell & 37,9 & 35 casas $(1910)$ \\
\hline Sella & 38,72 & casas despoblados & 153 casas \\
\hline
\end{tabular}

Fuente: elaboración propia a partir de Fabian y Fuero (1791), Orozco Sánchez (1878) y Figueras Pacheco (1913-1925).

El modelo económico preindustrial de la montaña era complejo y se componía de diversas actividades entrelazadas, ya que junto a la comercialización de producciones agrarias (cereal, almendra, aceite y vino, principalmente) la ganadería, los aprovechamientos forestales y las manufacturas a domicilio - el textil y esparto- podían representar ingresos de primer orden para familias o pueblos enteros (Marco, 2010). Pero el proceso de industrialización y urbanización, junto con la revolución de los transportes y los cambios políti- 
cos, fue alterando este modelo económico hacia una especialización productiva territorial en la que muchas de estas actividades adquirieron un papel secundario. Entre las décadas finales del siglo XIX y principios del Xx, hay unanimidad en afirmar que se asiste a la desintegración de las sociedades campesinas tradicionales de la montaña mediterránea y atlántica (Pérez Picazo, 1994; Lasanta, 2002), proceso en el que un nuevo orden económico debilitará la pluriactividad y los usos comunales representativos de las sociedades campesinas tradicionales.

La expansión vitícola, especialmente a partir de la década de 1860 gracias en parte a la plaga de filoxera en los viñedos franceses, incrementó la construcción de nuevas terrazas y coincidió con la supresión de medidas protectoras de los espacios incultos, debilitando el modelo de integración agrosilvopastoril ${ }^{4}$. La intensificación del aprovechamiento de los recursos incrementó la presión sobre el monte. Garrabou (1985) ofrece datos clarificadores: en el último tercio del siglo XIX se estima una reducción de unas 44.000 ha de montes y pastos en la provincia de Alicante, cifras que también deben vincularse a la disminución de cabezas de ganado con la decadencia de antiguas formas de explotación ganadera trashumante, en parte por la introducción del guano y otros fertilizantes externos. También parece que los incendios forestales eran comunes, como se recogen en diversos testimonios (Montiel, 1994; prensa histórica), aunque también existen evidencias documentales de una explotación forestal continuada, tal y como se comprueba en el Barranc de l'Arc (Benimantell): en 1877 se subastaba madera y esos mismos pinares maderables todavía suponían una importante fuente de ingresos para sus propietarios en 1880 y $1894^{5}$.

La filoxera llegó al área de estudio entre 1905 y 1910 (Piqueras, 2005) y aceleró los procesos de abandono de tierras, algunas de las cuales no volverían a roturarse desde entonces. Desarticuladas las estrategias productivas de las zonas de montaña y esquilmados los recursos naturales, el empobrecimiento y la superpoblación supuso el inicio de las primeras grandes oleadas migratorias hacia Argel, Francia o América, en un proceso que dominaría todo el siglo $\mathrm{xx}$.

\footnotetext{
${ }^{4}$ Hay testimonios contemporáneos que así lo evidencian (ca. 1890): «hasta las cumbres de las sierras (Aitana, Pantano, Cabeçó) dicen es realengo y como tal vendido, sin protesta ni por pastos, ni por leñas, ni por perder otros aprovechamientos» (ADA, Fondo Soler y Pérez, GD Mm40, pp. 22-23).

${ }^{5}$ Boletín Oficial de la Provincia de Alicante, 172 y 288.
} 


\section{Abandono progresivo y fin del poblamiento disperso (1920-1960)}

La plena inserción de la montaña en la economía de mercado supuso una evolución de sus objetivos productivos. Si el sistema tradicional permitía el aprovechamiento integral de todo el territorio, los cambios recientes implicaban la explotación intensiva de las áreas más fértiles y el abandono o explotación muy extensiva del resto del espacio. Esto supuso, además, inversiones de capital y aportes considerables de energía externa en forma de abonos químicos, mecanización y selección de variedades de cultivos más comercializables.

Durante la primera mitad del siglo xx la Serra d'Aitana todavía mantuvo altos índices de población, pero también de subocupación y bajas remuneraciones. El trascendental desarrollo de los transportes (carreteras y ferrocarril) supone un cambio de los circuitos comerciales, pero también la penetración de la influencia urbana, que invita a cientos de jóvenes a abandonar el medio rural. La conexión entre el litoral y el interior industrial se consolidó mediante la construcción de la carretera que cruza La Vall de Guadalest y la conexión entre Alcoi y La Vila Joiosa, aunque la carretera litoral que une Alacant con València y el ferrocarril Alcoi-Gandia contribuyeron a mantener el aislamiento del interior e impulsaron a la emigración. Igualmente, se produjo una progresiva reducción del poblamiento diseminado: entre 1900 y 1970 descendió del 30,6\% a 11,5\% en la Marina Baixa (Quereda, 1978: 339), aunque el proceso se aceleró especialmente a partir de la década de 1960.

A pesar de ello, en la agricultura se incrementó el proceso de especialización (almendro y olivo) con la potenciación de monocultivos en algunas zonas (cítricos en las vegas más templadas, níspero, cerezos), aunque en una primera fase todavía predominó el cereal y se conservó el policultivo de subsistencia, junto con la población dispersa. Pese a la crisis de la agricultura tradicional, parte de la población se mantuvo gracias a la explotación intensiva de las tierras más productivas, los complementos ofrecidos por la industria manufacturera (textil alcoyano) o el acceso a la propiedad que permitieron los ahorros reunidos por la emigración a países extranjeros. La coyuntura bélica nacional e internacional también fueron poderosos factores que ayudaron a retener población en el medio rural entre las décadas de 1930 y 1940, e incluso a roturar de nuevo campos abandonados. No obstante, algunas de las tierras menos fértiles o con suelos raquíticos, cultivadas con la expansión vitícola, comenzaron a reforestarse, existiendo incluso una actividad maderera remarcable. A pesar de la intensa degradación de la vegetación proveniente de décadas anteriores, se conservaban pinares abiertos mientras disminuía progresivamente la presión de la ganadería y el carboneo. De igual forma, la 
Figura 4

EVOLUCIÓN DE LA DENSIDAD DE POBLACIÓN

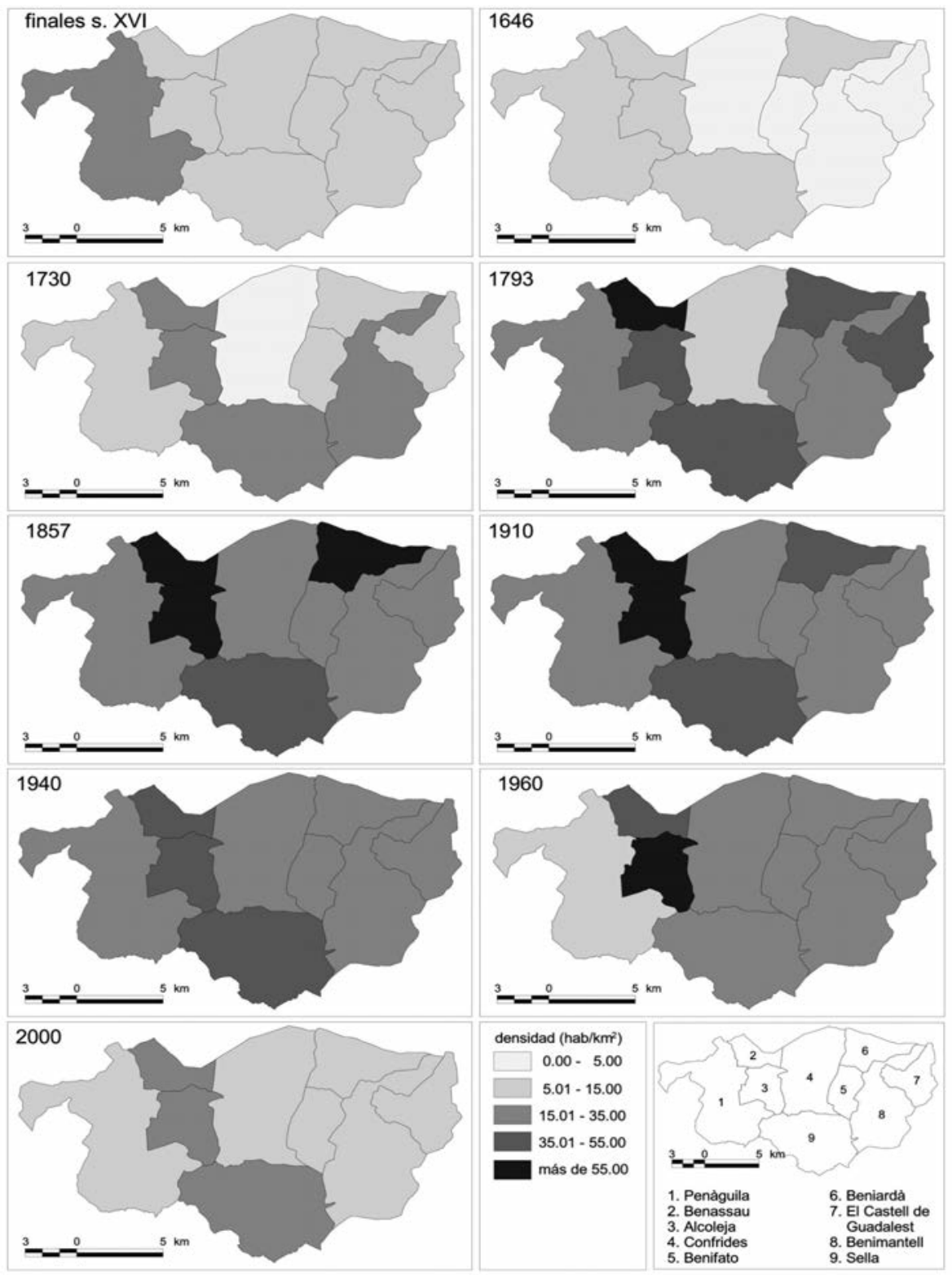

Fuente: elaboración propia a partir de Pla (1991) y Bernat y Badenes (1994). 
autarquía económica promovida desde el Gobierno, favoreció la recolección de esparto y las repoblaciones subvencionadas, aunque con escasa significación en el área de estudio. La construcción de los embalses de Guadalest y Amadorio durante las décadas de 1940 y 1950, junto con la construcción de una base militar americana en la culminación de Aitana, aminoraron el impacto del éxodo rural, que se aceleró a partir de la década de 1960.

\section{Abandono generalizado, despoblación e incendios forestales (1960-2010)}

En este momento, la carencia de servicios en el medio rural y la baja rentabilidad de los cultivos de secano no resistieron la competencia salarial surgida en la costa (Alacant, Benidorm) y en las ciudades industriales próximas (Alcoi, Ibi), donde se instalaron industrias y servicios. Se produjo, con ello, una importante emigración de mano de obra que repercutió en un crecimiento vegetativo negativo y un descenso progresivo de la población, cada vez más envejecida. En algunos municipios, el retroceso en el número de habitantes alcanzó el 55\%, con una reducción drástica del poblamiento diseminado (Matarredona, 1996a). Con ello, los efectivos de población dedicados a la agricultura disminuyeron, a pesar de la creciente mecanización, mientras que la ganadería quedó seriamente reducida; se consuma, en definitiva, el declive de la agricultura de la montaña y la consiguiente degradación de los paisajes aterrazados. Valgan como indicativas las cifras de abandono en Guadalest y Beniardà, cuyos espacios agrícolas pasan de representar el 42,6\% del término municipal en 1956 al 24,69\% en 2000 (Bellot et al., 2007). La arboricultura, con el predominio de policultivo arbóreo de secano (olivo, almendro y, en menor medida, cerezo) se expandió desde finales de los años cincuenta a costa de los antiguos sembrados de cereal, cobrando fuerza la agricultura a tiempo parcial (Moltó, 2003).

Estas nuevas dinámicas socio-económicas han generado diversas repercusiones en el paisaje. El significativo retroceso de la superficie cultivada tiene una particular incidencia sobre parcelarios de reducidas dimensiones y terrenos marginales de fuertes pendientes. Esta contracción se ha acompañado de una doble dinámica, en la que destaca, de forma predominante, un proceso efectivo de recolonización natural y, en otros, algunos problemas localizados de erosión y pérdida de suelos (Padilla, 1998). La desaparición de los aprovechamientos del monte ha ocasionado la formación de grandes masas forestales densas y continuas, dominadas por especies arbóreas más frugales como Pinus halepensis o formaciones arbustivas y subarbustivas (estepares, aulagares o to- 
millares) que han incrementado el nivel de biomasa. En consecuencia, a partir de la década de 1970, empezó a generalizarse un nuevo fenómeno de consecuencias devastadoras: los incendios forestales de gran magnitud, que entre 1978 y 2002 quemaron en La Montaña de Alicante más de 38.000 ha (Cortés, 2009), 31.000 de las cuáles ardieron entre 1981 y 1995 (Matarredona, 1996b). Se trata de décadas en las que también se incrementan las repoblaciones forestales en la Serra d'Aitana (Marco, 2001) y en las que predominan los pinos (Pinus halepensis, principalmente, pero también Pinus pinaster y Pinus nigra subsp. salzmanii).

Junto con todo ello, las nuevas dinámicas territoriales relacionadas con el turismo rural, la difusión de los usos residenciales o la aplicación de políticas de desarrollo rural integrado alrededor de la iniciativa comunitaria LEADER (Hernández et al., 2008) han acelerado la práctica disolución del medio rural, entendido como resultado de las actividades ligadas a la explotación tradicional de los recursos naturales. Junto con la desatención de los espacios de monte, la práctica desaparición de la actividad ganadera y el abandono de cultivos de secano y de espacios de regadío histórico —-desvaneciéndose incluso la organización plurisecular comunitaria de los usos del agua-, en la última década ha proliferado el uso masivo de herbicidas como alternativa al laboreo.

SÍNTESIS DE CAMBIOS SOBRE EL PAISAJE VEGETAL ¿HACIA LA DEGRADACIÓN?

Los resultados obtenidos permiten inferir los principales factores de cambio en el paisaje y sus consecuencias sobre la vegetación, que se enmarcan en el proceso generalizado de degradación documentado para la Europa mediterránea (McNeill, 1994; Grove y Rackham, 2001) y, más concretamente en tierras valencianas (Montiel, 1994; Ferrer, 2008). Los datos disponibles para la Serra d'Aitana ayudan a detectar el momento de máxima perturbación de la vegetación en el periodo comprendido entre 1850 y 1920, aunque se trata obviamente de un proceso acumulativo y muy antiguo, debido al intenso poblamiento y a la importancia ganadera de esta sierra en época medieval, cuando no anterior. El fuego como herramienta para obtención de pastos, las roturaciones y el aprovechamiento de los recursos forestales siguen una trayectoria cíclica de intensificación y desintensificación relacionada con la presión demográfica, el tipo de actividad económica predominante, los aspectos jurisdiccionales o la estabilidad social, factores que se repiten a lo largo de la Historia y con las diferentes culturas que han poblado este espacio. 
FIGURA 5

\section{SÍNTESIS DE PROCESOS ANALIZADOS}
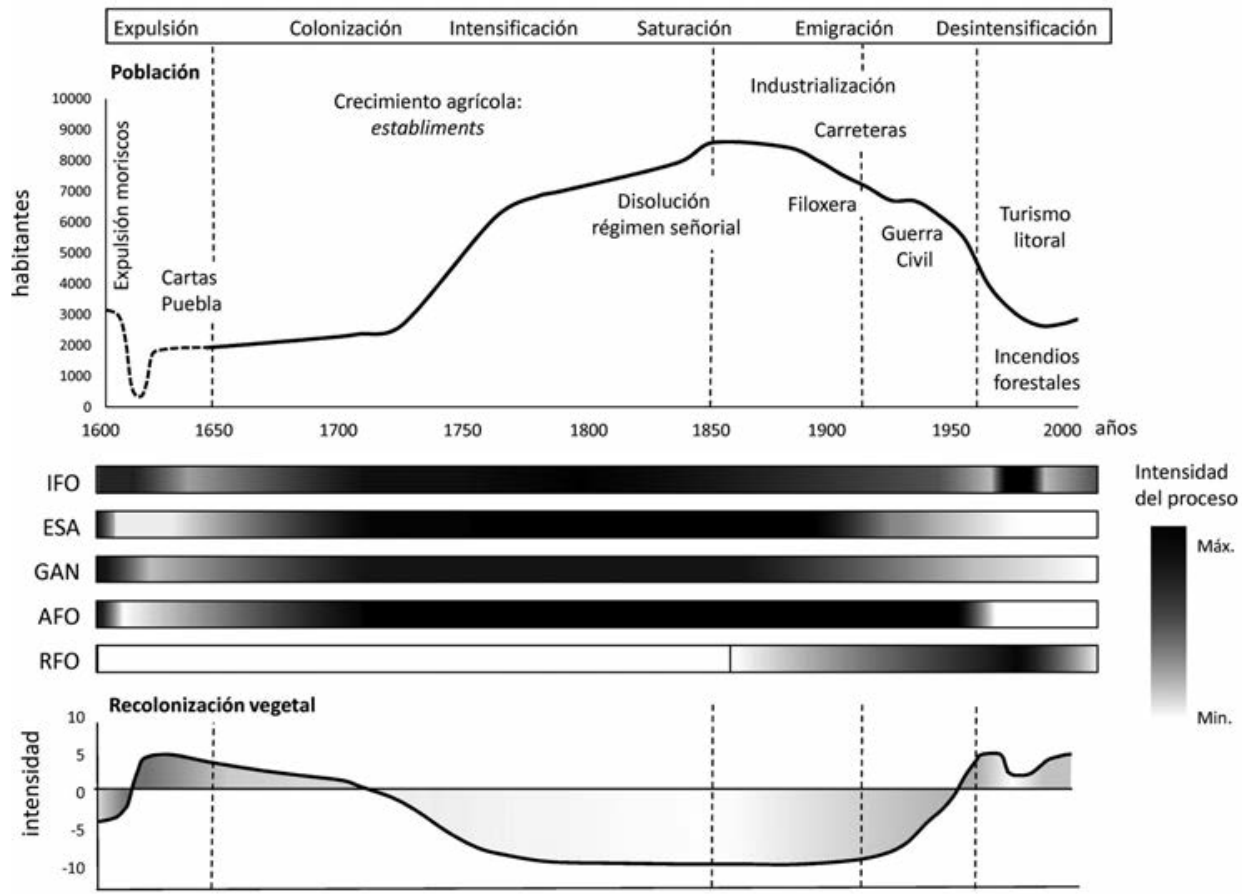

Fuente: elaboración propia a partir de de Pla (1991) y Bernat y Badenes (1994) para la demografía. Intensidad cualitativa y cuantitativa a partir de la recopilación de referencias documentales para los siguientes procesos: incendios forestales (IFO); expansión de la superficie agraria (ESA); ganadería (GAN); aprovechamientos forestales (AFO); repoblaciones forestales (RFO).

No obstante esto el siglo XVII representa, en nuestro ámbito de estudio, un momento de cambio relevante con ciertas ventajas para la investigación: documentación relativamente abundante y suficiente distancia temporal para adoptar cierta perspectiva sobre la respuesta de la vegetación a determinadas perturbaciones de origen humano. De esta forma, la síntesis presentada permite ofrecer unas claves iniciales para la comprensión de las comunidades vegetales de substitución predominantes en la actualidad, cuyo origen es muy anterior (Ntinou et al., 2013) pero que tienen en la intensa deforestación de los siglos XVIII y XIX un momento clave (Ferrer, 2004). Igualmente, el caso de Aitana permite establecer unas tendencias de cambio ampliables al conjunto de la denominada Muntanya d'Alacant, heredera del Quartel de la Marina y las 
Montañas anteriormente descrito. Conscientemente se ha querido obviar la posible incidencia de la Pequeña Edad Glaciar en las temperaturas y el tipo y cantidad de precipitación, por no tener elementos sólidos de interpretación.

Hasta los inicios del siglo Xvil destacaba todavía la actividad ganadera, especialmente importante en la edad Media e inicios de la Moderna, que repercutió sobre la vegetación a través del ramoneo - ganados mitxos- y, especialmente, el fuego - con presencia incluso de cremadors profesionales en el s. XIV-; destacan también las fases expansivas y regresivas de la agricultura, con incremento del secano desde el siglo XIV; o las guerras y la conflictividad social (revuelta de las Germanías, levantamientos moriscos), que también pueden ser un poderoso factor de degradación de la vegetación por la presencia de incendios intencionados y la suspensión de la gestión eficiente de los recursos (Butzer, 2005). A partir de 1609, con el despoblamiento casi absoluto, se constata una recuperación de la vegetación natural sobre campos de cultivos abandonados — como vemos en informes de la década de 1620-1630 sobre el estado de abandono generalizado- y los montes, dinámica que predominará hasta que comience a consolidarse el proceso colonizador.

En la mayoría de Cartas Puebla se especifica la reserva señorial del inculto, aunque el detalle del mismo es escaso: puntualmente se citan especies como carrascas -algunas forman parte del espacio agrario-, olmos blancos y negros, álamos o pinos (Guinot y Ardit, 2015). La fauna de ungulados silvestres es otro indicador indirecto de la presencia y extensión de zonas poco cultivadas y poco habitadas: Escolano (1611) cita, en las inmediaciones de la Serra d'Aitana (Estret del Pantà de Relleu), al ciervo y la cabra montés.

Entre 1680-1850, se apunta a una degradación generalizada de la vegetación natural, como señalan de numerosos testimonios documentales de diversa índole (Giménez-Font, 2008). Los estudios sobre la historia forestal valenciana, realizados principalmente a partir de los informes de Marina (Ferrer, 1997 y 2004; Laguna, 2002), dejan bien patente esta circunstancia. Dichos informes, compuestos por datos obtenidos en las distintas visuras realizadas entre 1748 y 1781, indican un paulatino cambio en el paisaje vegetal valenciano. Lamentablemente, la información sobre nuestra área de estudio es muy escasa y todavía está por explotar en archivos locales y nacionales. No obstante, los datos recopilados para el conjunto de las tierras valencianas $\mathrm{y}$, en concreto, para la provincia de Alicante, demuestran cómo, junto a la completa destrucción de la vegetación natural a causa de las roturaciones, las formaciones de quercíneas fueron paulatinamente sustituidas por pinos (Ferrer, 2004). Algunos autores estiman que la comparación de los datos indicativos del descenso de carrascales y formaciones mixtas con la actualidad, 
globalmente indica cómo se han multiplicado por cuatro el número de pies arbóreos, aunque con el mencionado predominio del género Pinus (Reyna y Fernández, 1998; Currás, 2001).

No obstante esto, los máximos niveles de deforestación se alcanzaron en el período 1850-1920, como en general ocurre en las montañas sur valencianas. La expansión de la agricultura, el creciente consumo de carbón y leña y la concentración de la presión ganadera son los principales factores de transformación. Los procesos desamortizadores y los cambios en la titularidad de los montes aceleraron un proceso de descuaje y deforestación generalizado, acompañado de elevados crecimientos demográficos y expansión masiva de la agricultura comercial. Fruto de la presión ejercida por las actividades descritas (labrado, pastoreo, carboneo, desrame y podas abusivas), incluso la vegetación de las zonas más elevadas presentaba una elevada degradación, con evidencias de la presencia constante del fuego: la Clasificación General de los Montes Públicos de 1859 ofrece información sobre las 44 ha de la «Muela de Aitana» (Confrides), donde la aliaga era la especie dominante, acompañada de «romero, tomillo y coscoja» (Ministerio de Fomento, 1859, p. 8). Es también durante este periodo cuando la fauna sufre su máxima degradación, llegando a la extinción de ciervo, cabra montesa e incluso del jabalí, mientras que el avistamiento de lobo ya resultaba a mediados del XIX un hecho excepcional (Jiménez, 2012).

Con todo, algunos sectores mantuvieron su dedicación forestal incluso en los momentos de mayor presión roturadora. Los documentos referidos al Barranc de l'Arc — que ya abastecía de madera al Marquesat de Guadalest a mediados del siglo xviII - nos hablan de pinares «de primera y de segunda» y «monte con leñas bajas y pinos y encinas» en las umbrías ${ }^{6}$. Aunque escasas, no eran formaciones excepcionales, aunque los rodales de arbolado existente tenían un aspecto de bosque abierto, con podas significativas y portes reducidos.

El inicio progresivo del abandono de campos de cultivo, la reducción del pastoreo y la disminución del aprovechamiento forestal con el desarrollo de nuevas fuentes energéticas, principalmente el butano, caracterizan el periodo posterior, que alcanzaría la década de 1960. Se produjo así un proceso de paulatina desintensificación, aunque marcado temporalmente por el contexto bélico de la Guerra Civil y la postguerra, momento en el que se pusieron en cultivo antiguos terrazgos abandonados. Aunque en la década de 1930 se de-

\footnotetext{
${ }^{6}$ Boletín Oficial de la Provincia de Alicante, 172, 18 de julio de 1880

7 Ver los Informes de los Distritos Forestales descritos por Montiel (1994).
} 
nuncia el mal estado de la vegetación ${ }^{7}$ se inició un proceso de reforestación, principalmente en las tierras más marginales. Predominaban pinares jóvenes o crecimientos de formaciones mixtas más complejas a partir de los rodales o bosquetes que habían sobrevivido a etapas anteriores. En algunos sectores se mantenía la explotación maderera, que destaca entre las décadas de 1940 y 1950. Posteriormente se generalizó el abandono de la economía rural tradicional, lo que implicó una homogeneización del paisaje caracterizada por un crecimiento de la superficie forestal en detrimento de los espacios abiertos (pastos y campos de cultivo). Igualmente existía una importancia puntual de las repoblaciones en el cantil septentrional de Aitana y en La Serrella con consecuencias perjudiciales para formaciones vegetales singulares, al alterar el substrato y los niveles de insolación necesarios para determinados taxones raros o endémicos. Esta pérdida puntual pero significativa de biodiversidad no es, con todo, el proceso más determinante de cuantos han ocurrido recientemente. En términos generales, el desmantelamiento del mundo rural tradicional ha supuesto la casi desaparición de ganados y animales de labor, de los sembrados y de la diversidad varietal de cereales, legumbres, hortalizas y árboles frutales adaptados a las condiciones topoecológicas de cada sector de la sierra. La dinámica de regeneración natural vinculada al abandono de usos agropecuarios ha impulsado el incremento de incendios forestales, lo cual ha favorecido las etapas substitutivas dominadas por especies pirófitas y pioneras (leguminosas como Ulex parviflorus, cistáceas como Cistus albidus, labiadas o el propio pino carrasco). No obstante, el abandono del aprovechamiento de leñas y carbón, junto al descenso de la ganadería, ha favorecido una tendencia positiva de recolonización vegetal hacia formaciones más complejas y maduras que han modificado el hábitat de algunas especies animales. En la década de 1970 comenzaron los primeros avistamientos de jabalí, que en la actualidad presenta densidades muy elevadas (Belda, et al., 2012). Durante esa década la presencia del Safari-Park de Aitana y de cotos cinegéticos como El Regall, en el sector occidental de la sierra, ocasionaron fugas de ungulados autóctonos como el ciervo y otros herbívoros exóticos como el gamo y el muflón. Pero no es hasta la década de 2000 cuando estas poblaciones empiezan a ser viables coexistiendo con la invasión del arruí, procedente también de cotos cinegéticos (Jiménez, 2012). La práctica desaparición de los ganados viene a coincidir con el surgimiento de estos herbívoros, aunque con un impacto menor sobre la vegetación. 
FIGURA 6

COMPARACIÓN DEL ESTADO DEL ENTORNO DEL PORT DE TUDONS (ALCOLEJA) ENTRE 1890 (A) Y 2006 (B), CON LA QUE SE CORROBORA LA TENDENCIA POSITIVA DE LA RECOLONIZACIÓN VEGETAL EN LA ACTUALIDAD
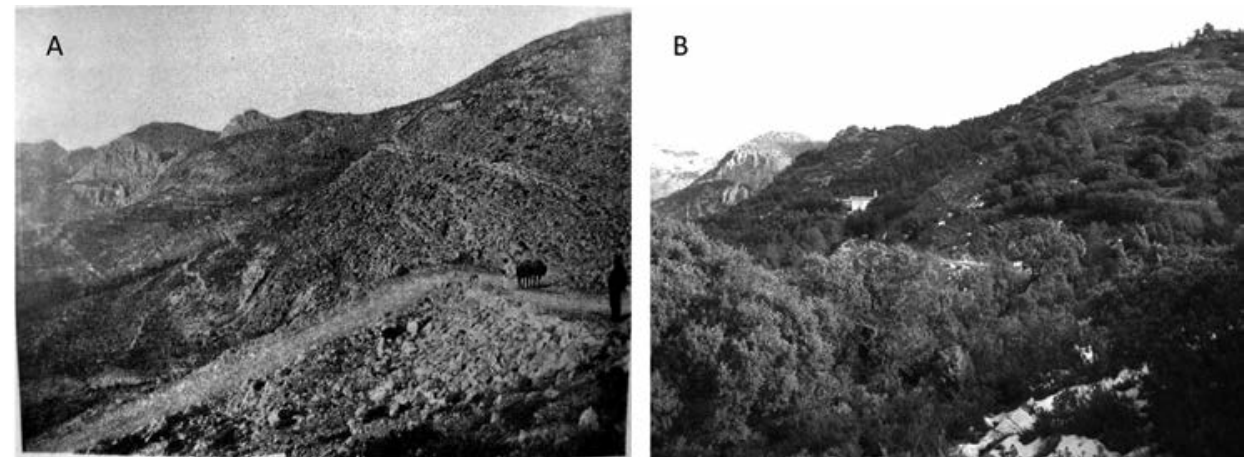

Fuente: Figueras Pacheco (1913-25) y elaboración propia.

\section{CONCLUSiOnes}

En el planteamiento general expuesto en la introducción se hacía referencia a la necesidad de reconstruir la historia reciente de un ecosistema para valorar correctamente su capacidad de respuesta ante determinadas perturbaciones, especialmente si éstas tienen un carácter antropogénico. Para ello las perspectivas temporales que alcancen, como mínimo, los últimos cuatro siglos, resultan fundamentales. De esta forma, un estudio detallado como el realizado para la Serra d'Aitana ha permitido sintetizar los factores de alteración de la vegetación y localizarlos temporalmente: factores relacionados con cambios culturales, jurisdiccionales, económicos y socioecológicos que, debidamente trabados entre sí y con las características del medio, permiten centrar posteriores análisis sobre el peso de cada factor en diferentes lugares y contextos. Se trata, así, de configurar un marco analítico general, válido para el resto de los sectores montañosos valencianos, sobre el cual desarrollar estudios de detalle que permitan afinar este planteamiento inicial.

La periodización realizada permite reconstruir una trayectoria de la vegetación que coincide a grandes rasgos con los planteamientos generales realizados para la cuenca del Mediterráneo europeo. Las particularidades de esta zona de estudio derivan, con todo, de la inestabilidad producida entre finales 
del siglo XVI e inicios del XVII con la expulsión de gran parte de sus habitantes. No solo significó este hecho un proceso de recuperación vegetal durante, al menos los primeros 50 años tras la extrañación morisca, sino que la colonización cristiana posterior, durante el siglo xvIII, significó la consolidación de un patrón de usos del suelo que nacía de la propia conquista medieval. La expansión de la agricultura comercial y el incremento de la población alcanzaron los límites de saturación a mediados del siglo XIX y se prolongó hasta los inicios del siglo xx. La máxima presión sobre la vegetación natural, especialmente intensa entre 1750 y 1890, supuso altas tasas de deforestación y permite fijar en este momento el principal momento de perturbación de la serie estudiada. Durante el siglo xx, destaca un proceso de recuperación que se acelera, incluyendo a la fauna, en paralelo al proceso de desmantelamiento del mundo rural. La pérdida de la biodiversidad agraria se acompaña de la recuperación y densificación de formaciones forestales que, durante la década de 1980 y 1990, son arrasadas por incendios forestales. La presencia de estos fuegos descontrolados y generalizados junto con la ausencia de ganadería ha facilitado el desarrollo de densas formaciones que, dependiendo del sector de la sierra, tienden hacia el óptimo o todavía son predominantemente de substitución. La reforestación, en paralelo al abandono de la agricultura y la ganadería, supone también un cambio de las condiciones ecológicas y del propio hábitat de numerosas especies animales y vegetales, aunque la amenaza de incendios forestales puede detener o alterar este proceso de renaturalización del paisaje vegetal tan característico de la montaña mediterránea europea.

\section{FUENTES DOCUMENTALES Y BIBLIOGRAFÍA}

\section{Archivos, secciones y fondos documentales consultados}

Arxiu del Regne de València (València) (ARV), Batlía General, Intendència.

Archivo Histórico Nacional (Madrid), (AHN) Consejos.

Archivo de la Diputación de Alicante (ADA), Fondo Eduardo Soler, Fomento; Patrimonio Forestal del Estado.

Archivo Histórico Provincial de Alicante (AHPA), Hacienda, Boletín Oficial de la Provincia de Alicante (BOPA).

Arxiu Municipal de La Vila Joiosa (Alicante) (AMV), Libros de Deliberaciones, Montes.

Archivo del Palacio Real (Madrid) (APR), Administración.

Portal de Prensa Histórica (Ministerio de Cultura) y Hemeroteca digital (Biblioteca 
Nacional de España).

Instituto Geográfico Nacional, Minutas cartográficas (Bosquejos planimétricos por términos municipales, 1899-1901) [documento cartográfico], escala 1:25.000, Alicante-Madrid.

\section{Fuentes históricas impresas}

Castañeda y Alcover, V. (1919): Relaciones Geográficas, Topográficas e Históricas del Reino de Valencia de Tomás López. S (XVIII) [ed. facsímil de la Generalitat Valenciana, 1998, 2 vols.].

Cavanilles, A. J. (1795-1797): Observaciones sobre la Historia Natural, Geografía, Agricultura, Población y Frutos del Reyno de Valencia, Madrid, Imprenta Real, 2 vols. [ed. facsímil, Biblioteca Valentina, 1975, 574 pp.]

Escolano, G. (1611): Décadas de la historia de la insigne y coronada ciudad y Reino de Valencia [edición facsímil Librerías París-Valencia, 1980, 3 vols.].

Fabian y Fuero, F. (1791): Informe del Arzobispo Fabian y Fuero al ministro Conde de Floridablanca sobre la diócesis de Valencia, Original manuscrito depositado en el Ministerio de Asuntos Exteriores (Madrid), Manuscritos 35 y 36.

Figueras Pacheco, F. (1913-1925): "Provincia de Alicante" en F. Carreras y Candi (coord.), Geografía General del Reino de Valencia, vol. V., Barcelona, Alberto Martín, $1.210 \mathrm{pp}$.

Lacroix y Vidal, J. (1801): Memoria que contiene la indicación de los montes del Reyno de Valencia, Valencia, Imp. Benito Monfort, 107 pp.

Madoz, P. (1845): Diccionario geográfico-estadístico-histórico de España y sus posesiones de ultramar, 16 vols, Madrid, Imp. del Diccionario.

Martí i Gadea, J. (1908): Tipos, Modismes y Còses Rares y Curioses de la tèrra del Gè, València, Imp. de Antonio López, [edición facsímil Librerías París-Valencia, 1993, 411 pp.]

Ministerio de Fomento (1859): Clasificación General de los Montes Públicos, Madrid, Imprenta Nacional.

Miñano Bedoya, S. (1826-29): Diccionario geográfico-estadístico de España y Portugal, 11 vols., Madrid, Pierart-Peralta,

Nipho, J. M. (1770-1771): Correo general de España, y noticias importantes de agricultura, artes, manufacturas, comercio, industria y ciencias, Madrid [ed. facsímil del Ministerio de Agricultura, Pesca y Alimentación, 1988, 4 vols.].

Orozco Sánchez, D. P. (1878): Manual Geográfico-Estadístico de la Provincia de Alicante, Alicante, Imprenta de Antonio Reus, 272 pp. 


\section{Bibliografía}

Agnoletti, M. (2007): "The degradation of traditional landscape in a mountain area of Tuscany during the 19th and 20th centuries: Implications for biodiversity and sustainable management", Forest Ecology and Management, 249, pp. 5-17.

Agnoletti, M. (2014): "Rural landscape, nature conservation and culture: Some notes on research trends and management approaches from a (southern) European perspective", Landscape and Urban Planning, 126, pp. 66-73.

Antrop, M. (2005): "Why landscapes of the past are important for the future", Landscape and Urban Planning, 70, pp. 21-34.

Asins, S. (2009): El paisaje agrario aterrazado. Diálogo entre el hombre y el medio en Petrer (Alicante), Valencia, Universidad de Valencia, 359 pp.

Bauer-Manderscheid, E. (1980): Los montes de España en la Historia, Madrid, Ministerio de Agricultura, $610 \mathrm{pp}$.

Belda, A., Zaragozí, B., Martínez-Pérez, J. E., Peiró, V., Ramón, A., Seva, E. y Arques, J. (2012): "Use of GIS to predict potential distribution areas for wild boar (Sus scrofa Linnaeus 1758) in Mediterranean regions (SE Spain)", Italian Journal of Zoology, 79/2, pp. 252-265.

Bellot, J., Bonet, A., Peña, J. y Sánchez, J. R. (2007): "Human Impacts on Land Cover and Water Balances in a Coastal Mediterranean County", Environmental Management, 39, pp. 412-422.

Bernat, J. S. y Badenes, M. A. (1994): Crecimiento de la población valenciana (16091857), València, Edicions Alfons el Magnànim, 360 pp.

Braudel, F. (1953): El Mediterráneo y el mundo mediterráneo en la época de Felipe II (vol. 1), México, Fondo de Cultura Económica, 860 pp.

Butzer, K. W. (2005): "Enviromental history in the Mediterranean world: cross-disciplinay investigation of cause-and-effect for degradation and soil erosion", Journal Archaeological Science, 32, pp. 1.773-1.800.

Corbalán de Celis, J. (2004): "La carta de nueva población y los establecimientos de la Vall de Tárbena en 1611", Boletín de la Sociedad Castellonense de Cultura, 80, pp. 239-258.

Cortés, C. (2009): Población y economía rural en la "Montaña de Alicante", Alicante, Universidad de Alicante, 503 pp.

Currás, R. (2001): "El ayer de los montes valencianos: breve reseña histórica" en Anales Real Sociedad Económica de Amigos del País 1999-2000, Valencia, RSEAPV, pp. 639-651.

Doblas-Miranda, E., Martínez-Vilalta, J., Lloret, F., Álvarez, A., Ávila, A., Bonet, F. J., Brotons, L., Castro, J., CurielYuste, J., Díaz, M., Ferrandis, P., García-Hurtado, E., Iriondo, J. M., Keenan, T. F., Latron, J., Llusià, J., Loepfe, L., Mayol, M., Moré, G., Moya, D., Peñuelas, J., Pons, X., Poyatos, R., Sardans, J., Sus, O., Vallejo, V. R., Vayreda, J. y Retana, J. (2015): "Reassessing global change research priorities in 
mediterranean terrestrial ecosystems: how far have we come and where do we go from here?", Global Ecology and Biogeography, 24, pp. 25-43.

Ferrer, V. (2004): "La cubierta arbórea de los montes valencianos en el siglo XVIII a partir de los informes de Marina", Boletín de la Sociedad Castellonense de Cultura, 80, pp. 307-353.

Ferrer, V. (2008): "Una hipótesi sobre l aprofitament energètic dels boscos valencians a les darreries de 1 Antic Règim", Boletín de la Sociedad Castellonense de Cultura, 84, pp. 193-212.

Foster, D., Swanson, F., Aber, J., Burke, I., Brokaw, N., Tilman, D. y Knapp, A. (2003): "The importance of land-use legacies to ecology and conservation", BioScience, 53/1, pp. 77-88.

García Cárcel, R. (1977): "La ganadería valenciana en el siglo Xvı", Saitabi, 18, pp. 171-188.

García Fernández, J. (2002): "La explotación de los montes y la humanización del paisaje vegetal (cuestiones de método previas)", Investigaciones Geográficas, 29, pp. 5-21.

Garrabou, R. (1985): Un fals dilema. Modernitat o endarreriment de l'agricultura valenciana (1850/1900), València, Alfons el Magnànim, 224 pp.

Gil Olcina, A. (1988): "Declive y ocaso de la enfiteusis señorial valenciana", Agricultura y Sociedad, 49, pp. 293-318.

Giménez-Font, P. (2008): Las transformaciones del paisaje valenciano en el siglo XVIII. Una perspectiva geográfica, Valencia, Alfons el Magnànim, 405 pp.

Giménez-Font, P. (2010): "Las imágenes del paisaje. Arte y fotografía en la obra de los hermanos Soler y Pérez" en F. Cortés y P. Giménez (eds.), Eduardo Soler y Pérez. Un jurista en el Paisaje, Alicante, I.E.A. Juan Gil-Albert, pp. 119-135.

Giménez-Font, P. (2013): "La dinàmica del paisatge de terrasses de cultiu: algunes reflexions per al seu estudi a la serra d'Aitana (País Valencià)", Quaderns Agraris, 34, pp. 83-98.

Glick, T. F. (2007): Paisajes de conquista. Cambio cultural y geográfico en la España medieval, Valencia, Universidad de Valencia, $253 \mathrm{pp}$.

Grove, A. T. y Rackham, O. (2001): The Nature of Mediterranean Europe. An Ecological History, New Haven, CT, Ed. Yale University Press, 384 pp.

Guinot, E. y Ardit, M. (eds.) (2015): Cartes de poblament valencianes modernes (segles XVI-XVIII), València, Universitat de València, 1.801 pp.

Hernández, M., Moltó, E. y Rico, A. (2008): "Las actividades turístico-residenciales en las montañas valencianas", Eria, 75, pp. 77-97.

Horden, P. y Purcell, N. (2000): The Corrupting Sea. A Study of Mediterranean History, Oxford, Blackwell Publishing, 761 pp.

Jiménez, J. (2012): "Extinción, recuperación e introducción de mamíferos en la Comunitat Valenciana. Cambios en la fauna y acción humana”, en J. Jiménez, M. A. Monsalve y J. A. Raga (eds.), Mamíferos de la Comunitat Valenciana, Valencia, Conselleria d'Infraestructures, Territori i Medi Ambient. Generalitat Valenciana, pp. 19-47. Colección Biodiversidad, 19. 
Kull, C. A. (2005): "Historical landscape repeat photography as a tool for land use change research", Norwegian Journal of Geography, 59, pp. 253-268.

Laguna, E. (2002): "Los árboles singulares en el medio natural valenciano durante la Ilustración" en Los árboles de la ilustración en el paisaje forestal, Valencia, RSEAPV, pp. $520-531$

Lasanta, T. (2002): "Los sistemas de gestión en el Pirineo central español durante el siglo xx: del aprovechamiento global de los recursos a la descoordinación espacial en los usos del suelo", Ager, 2, pp. 173-195.

Lasanta, T., Nadal Romero, E., Errea, P. y Arnáez, J. (2016): "The effect of landscape conservation measures in changing landscape patterns: a case study in mediterranean mountains", Land Degradation \& Development, 27/2, pp. 373-386.

Lasanta, T., Vicente-Serrano, S. M. y Cuadrat, J. M. (2005): "Mountain Mediterranean landscape evolution caused by the abandonment of traditional primary activities: a study of the Spanish Central Pyrenees", Applied Geography, 25/1, pp. 47-65.

Marco, J. A. (1989): El medio físico de Aitana: análisis morfoestructural, condiciones bioclimáticas y formas del modelado, Alicante, Instituto Universitario de Geografía, Universidad de Alicante, 3 vols., 768 pp.

Marco, J. A. (1990): Aitana. Análisis morfoestructural, Alicante, I. C. Juan Gil-Albert, $120 \mathrm{pp}$.

Marco, J. A. (2001): Aitana como espacio singular. Perspectiva geográfica de una montaña mediterránea, Alicante, Universidad de Alicante, 107 pp.

Marco, J. A. (2010): El esparto y los atochares: una aproximación a su significado, aprovechamiento e impronta en el paisaje, San Vicent del Raspeig, Ajuntament-Cercle d'Estudis Sequet però Sanet, 66 pp.

Marco, J. A., Matarredona, E. y Padilla, A. (2000): Cartografía básica geomorfológica. E 1:100.000. Alacant (15-17), Alicante, Universidad de Alicante.

Marco, J. A. y Padilla, A. (eds.) (2002): Aportaciones recientes al conocimiento biogeográfico de Aitana (Alacant), Alicante, Universidad de Alicante, 129 pp.

Marco, J. A., Padilla, A. y Sánchez, A. (2006): "Cartografía corológica mediante el uso de GPS de especies endémicas, raras o amenazadas en el sector oriental de Aitana (Alacant)", Serie Geográfica, 13, pp. 11-24.

Martines, J., Martines, V. y Martinez-Solbes, J. P. (2011): Benimantell. La Vall de Guadalest, 1611-2011, La Vila Joiosa, Ajuntament de Benimantell, 260 pp.

Marull, J., Pino, J., Tello, E. y Mallarach, J. M. (2006): “Análisis estructural y funcional de la transformación del paisaje agrario en el Vallès durante los últimos 150 años (1853-2004): relaciones con el uso sostenible del territorio", Áreas, 25, pp. 105-126.

Matarredona, E. (1996a): "Atonía y agotamiento demográfico de la montaña alicantina”, Investigaciones Geográficas, 16, pp. 41-60.

Matarredona, E. (1996b): "Los incendios forestales: un riesgo candente en «La Montaña alicantina»", Investigaciones Geográficas, 16, pp. 157-168.

McNeill, J. R. (1994): The Mountains of the Mediterranean World: An Environmental History, New York, Cambridge University Press, 432 pp. 
Moltó, E. (2003): La agricultura a titulo parcial en la Montaña de Alicante, Alicante, Universidad de Alicante, 297 pp.

Montiel, C. (1994): "Decadencia y degradación de las masas forestales mediterráneas", Investigaciones Geográficas, 12, pp. 185-200.

Montiel, C. (1995): La propiedad forestal de raigambre señorial en tierras valencianas, Alicante, I. C. Juan Gil-Albert, 347 pp.

Naveh, Z. (1991): "Mediterranean uplands as anthropogenic perturbation dependent systems and their dynamic conservation management", en O. A. Ravera (ed.), Terrestial and Aquatic Ecosystems, perturbation and Recovery, New York, Ellis Horwood, pp. 544-556.

Ntinou, M., Badal, E., Carrión, Y., Menéndez, J. L., Ferrer, R. y Pina, J. (2013): “Wood use in a medieval village: the contribution of wood charcoal analysis to the history of land use during the 13th and 14th centuries AD at Pobla d'Ifach, Calp, Alicante, Spain", Vegetation history and archaeobotany, 22/2, pp. 115-128.

Obiol, E. (1997): "Les notícies ramaderes a les Observaciones del Reyno de Valencia d'A.J. Cabanilles", Cuadernos de Geografía, 62, pp. 387-402.

Padilla, A. (1998): Colonización vegetal en campos de cultivo abandonados en la provincia de Alicante, Alicante, Universidad de Alicante, 365 pp.

Padilla, A. (2006): "Las microrreservas vegetales, una figura para la protección de la flora rara, endémica o amenzada en la Comunidad Valenciana" en P. Giménez et al. (eds.), Geografía Física y Medio Ambiente, Alicante, Asociación de Geógrafos Españoles, pp. 141-156.

Pérez Picazo, M. T. (1994): "La disolución de las sociedades campesinas tradicionales en el mundo mediterráneo", en Agriculturas mediterráneas y mundo campesino: cambios históricos y retos actuales, Almería, Instituto de Estudios Almerienses, pp. 15-43.

Piqueras, J. (2005): "La filoxera en España y su difusión espacial: 1878-1926", Cuadernos de Geografía, 77, pp. 101-136.

Pla Alberola, P. (1983): La población del marquesado de Guadalest en el siglo XVII, Alicante, Caja de Ahorros Provincial, 218 pp.

Pla Alberola, P. (1991): "Despoblación y repoblación. La crisis del XVII en el Cuartel de La Marina y Las Montañas", en J. Nadal (ed.), Evolución demográfica bajo los Austrias, Alicante, I. C. Juan Gil-Albert, pp. 195-239.

Plieninger, T., Kizos, T., Bieling, C., Le Dû-Blayo L., Budniok, M. A., Bürgi, M., Crumley, C. L., Girod, G., Howard, P., Kolen, J., Kuemmerle, T., Milcinski, G., Palang, H., Trommler, K. y Verburg, P. H. (2015): "Exploring ecosystem-change and society through a landscape lens: recent progress in European landscape research", Ecology and Society, 20/2, p. 5.

Portús, J. y Vega, J. (1998): La estampa religiosa en la España del Antiguo Régimen, Madrid, Fundación Universitaria Española, 631 pp.

Poyatos, R., Latron, J. y Llorens, P. (2003): "Land Use and Land Cover Change After Agricultural Abandonment. The Case of a Mediterranean Mountain Area (Catalan Pre-Pyrenees)", Mountain Research and Development, 23/4, pp.362-368. 
Quereda, J. (1978): La comarca de La Marina, Alicante. Estudio de geografía regional, Alicante, Diputación Provincial, 431 pp.

Reyna, S. y Fernández, B. (1998): "Existencias de los montes valencianos en el siglo XVIII. Comparación con el $2^{\circ}$ Inventario Forestal Nacional", Revista de Montes, 51, pp. 88-93.

Torró, J. (1990): Poblament i espai rural. Transformacions històriques, València, Alfons el Magnànim, $132 \mathrm{pp}$.

Torró, J. (2005): "Terrasses irrigades a les muntanyes valencianes. Les transformacions de la colonització cristiana", Afers, 51, pp. 301-356.

Torró, J. (2006): El naixement d’una colònia. Dominació i resistència a la frontera valenciana (1238-1276), València, Universitat de València, 263 pp.

Vogiatzakis, I. N. y Papanastasis, V. P. (2012): "Land Use Changes", en I. N. Vogiatzakis, (ed.), Mediterranean Mountain Environments, Chichester, John Wiley \& Sons, pp. 159-184.

Fecha de recepción: 24 de junio de 2015.

Fecha de aceptación: 28 de enero de 2016. 